Journal of Applied Pharmaceutical Science Vol. 5 (11), pp. 113-116, November, 2015

Available online at http://www.japsonline.com

DOI: $10.7324 / \mathrm{JAPS} .2015 .501119$

ISSN 2231-3354 (cc) BY-NC-SA

\title{
Protective Effect of Helix aspersa Extract against Spleen and Liver Injuries Induced by N-Nitroso Methyl Urea in Mice
}

\author{
Ibtissem EL OUAR ${ }^{1 *}$, Hajer ATOUI ${ }^{1}$, Ihcène DRAA ${ }^{1}$, Cherifa AGGOUNE $^{1}$, Dalila NAIMI ${ }^{1,2}$ \\ ${ }^{1}$ Laboratory of microbiological engineering and application, University Mentouri Constantine. National high school of biotechnology , Ali Mendjli - \\ Constantine, Algeria. ${ }^{2}$ National high school of biotechnolog, Ali Mendjli-Constantine, Algeria.
}

\begin{tabular}{l} 
ARTICLE INFO \\
\hline Article history: \\
Received on: 01/08/2015 \\
Revised on: 29/08/2015 \\
Accepted on: 22/09/2015 \\
Available online: $27 / 11 / 2015$ \\
\hline Key words: \\
N-nitrosomethylurea, \\
carcinogenesis. Helix \\
aspersa, aqueous extract
\end{tabular}

\begin{abstract}
Objective: This study was carried out to investigate the protective effect of an aqueous extract, from the garden snail Helix aspersa (Mollusca, pulmonate), against N-nitrosomethylurea (NMU) induced damage in mice. Methods: Haematoxylin/ Eosin based histology was performed to evaluate the morphological changes in liver and spleen.

Results: our results show that NMU causes different damages in liver and spleen. It induces alterations of blood system of the two organs with the apparition of hemangioma. The histological assessment shows that $H$. aspersa extract markedly reduces the damage induced by the carcinogen and preserved the histo-architecture of these tissues. Furthermore, histopathological finding demonstrates that $H$. aspersa extract increase immune system activity through the stimulation of immune cell penetration in liver and differentiation of macrophages into foreign body giant cells.

Conclusion: These results suggest that $H$. aspersa extract acts as a potent hepatic and spleen protective agent against NMU carcinogenesis.
\end{abstract}

\section{INTRODUCTION}

N-Nitroso compounds were known almost 40 years ago to be present in food treated with sodium nitrite, which made fish meal hepatotoxic to animals through formation of nitrosodimethylamine. Since that time, $N$-nitroso compounds have been shown in animal experiments to be the most broadly acting and the most potent group of carcinogens (Lijinsky, 1999). Nitroso compounds can be divided into two main subclasses, nitrosamines and nitrosamides (Singer and Kusmierek, 1982), which are both capable of inducing alkylating DNA damage by the formation of a highly reactive diazonium ion (Mirvish, 1995; Tricker and Preussmann, 1991). O6-alkylguanine adducts have been identified as the main premutagenic lesion and cause GC- AT transition mutations (Mirvish, 1995). Experimental and epidemiological data suggest that human is susceptible to carcinogenesis by nitroso compounds. The presence of these compounds in food constitutes an etiological risk factor involved in different kinds of cancer like esophagus, stomach, nasophaynx and other sites (Kim et al., 2013; Mirvish, 2013).

\footnotetext{
* Corresponding Author

Emal: ibtissem_elouar@yahoo.fr
}

Recently, cancer chemopreventive potential of natural compounds is of great interest for its fewer side effects in living systems (Liu, 2004; Guru kumar, 2012). In this context our study was designed to evaluate the protective effect of an aqueous extract from $H$. aspersa on liver and spleen injuries induced by N-Nitroso methyl urea (NMU).

Helix aspersa (Mollusca, Pulmonata, Helicidae; Müller, 1774) is a big land snail and one of the most consumed species in the Mediterranean countries. The therapeutic effect of these animals has been reported since the antiquity they were used to purify blood and to treat conjctivitis, cardio vascular diseases and liver problems.

\section{MATERIAL AND METHODS}

Preparation of $\boldsymbol{H}$. aspersa extract: $H$. aspersa snails were maintained fasting during at least 2 weeks. Before use, the snails were washed in 3 or 4 bath of $\mathrm{NaCl}$ solution. After that, snails were dissected and homogenized; 3 volumes of water per one volume of wet tissues were added to the homogenate.

The crude extract was then, filtered and centrifuged for $10 \mathrm{mn}$ at $5000 \mathrm{~g}$. The supernatants were collected and sterilized using $22 \mu \mathrm{m}$ Millipore filter. 


\section{Animals}

Females Mus musculs mice $(18-22 \mathrm{~g})$ procured from Pasteur institute Algiers were housed in plastic cages at room temperature $\left(22 \pm 1{ }^{\circ} \mathrm{C}\right)$ under a $12 \mathrm{~h}$ light/dark cycle and provided with rodent chow and water. The animal studies were conducted after obtaining clearance from Institutional Animal Ethics Committee.

\section{Experimental design}

The mice were divided into four groups with 10 animals in each group and were given dose regimen as given below:

Group I: control animals were given normal saline solution $(0,9 \%)$

Group II: animals received every week a single dose of $50 \mathrm{mg} / \mathrm{kg}$

NMU diluted in $0.9 \%$ saline solution, then administrated intra peritoneally.

Group III: animals received every week a single dose of NMU (50 $\mathrm{mg} / \mathrm{kg}$, diluted in $0,9 \%$ saline solution) administrated intra peritoneally. The treatment by NMU, in the two groups, was lasted for 3 consecutive weeks.

One day after the last injection of NMU the animals of the third group, received every day, an intra peritoneal injection of $H$. aspersa aqueous extract at $0,15 \mathrm{~g} / \mathrm{ml} /$ mouse.

Group IV: animals received every day an intra peritoneal injection of $H$. aspersa aqueous extract at $0,15 \mathrm{~g} / \mathrm{ml} /$ mouse.

The treatment with the snail extract, in the two last groups, was lasted for 4 consecutive weeks.

\section{Histopathological studies}

Tissues for histopathological analysis were fixed in $10 \%$ buffered formalin saline, processed by routine histology procedure and embedded in paraffin. Tissues sections were then stained with
Hematoxylin/eosin and observed under light microscope OPTECH OPTICAL TECNOLOGY®. All reagents were purchased from Sigma Aldrich, Algeria.

\section{RESULTS}

\section{Effect on liver histology}

MNU primed mice showed illness symptoms like loss of weight, uneven shedding of hairs, the histopathological examination of the liver revealed that the normal structure was altered. Hepathocytes showed cytoplasmic degeneration and necrosis. Hepatic blood system was greatly affected; the carcinogen induces sinusoid dilatation associated with hemangioma (Fig 1B).

Mice with $H$. aspersa extract showed no changes in hepatic tissue architecture. Therefore an infiltration of immune cells has been observed (Fig 1C). Liver section of mice treated by NMU followed by $H$. aspersa extract showed a reparative effect, we noted a diminution of hepatocyte necrosis and a normal sinusoid (Fig 1C).

\section{Effect on spleen histology}

Primed mice by MNU showed a number of abnormalities (Fig 2B) such as capsule laceration (Fig 2b), with neutrophilic infiltration. Congestion and intraparenchymal hemorrhage were observed. NMU induces also a venous alteration like hemangioma (Fig 2c) Microscopic findings, in mice treated with $H$. aspersa extract (Fig 2C) included apparition of giant cells (Fig 2d and e) and a peri arteriolar amyloid deposition (Fig 2C). Section D in figure 2 showed normal spleen architecture in mice treated by MNU followed by the aqueous extract. It seems that $H$. aspersa extract have a reparative effect.
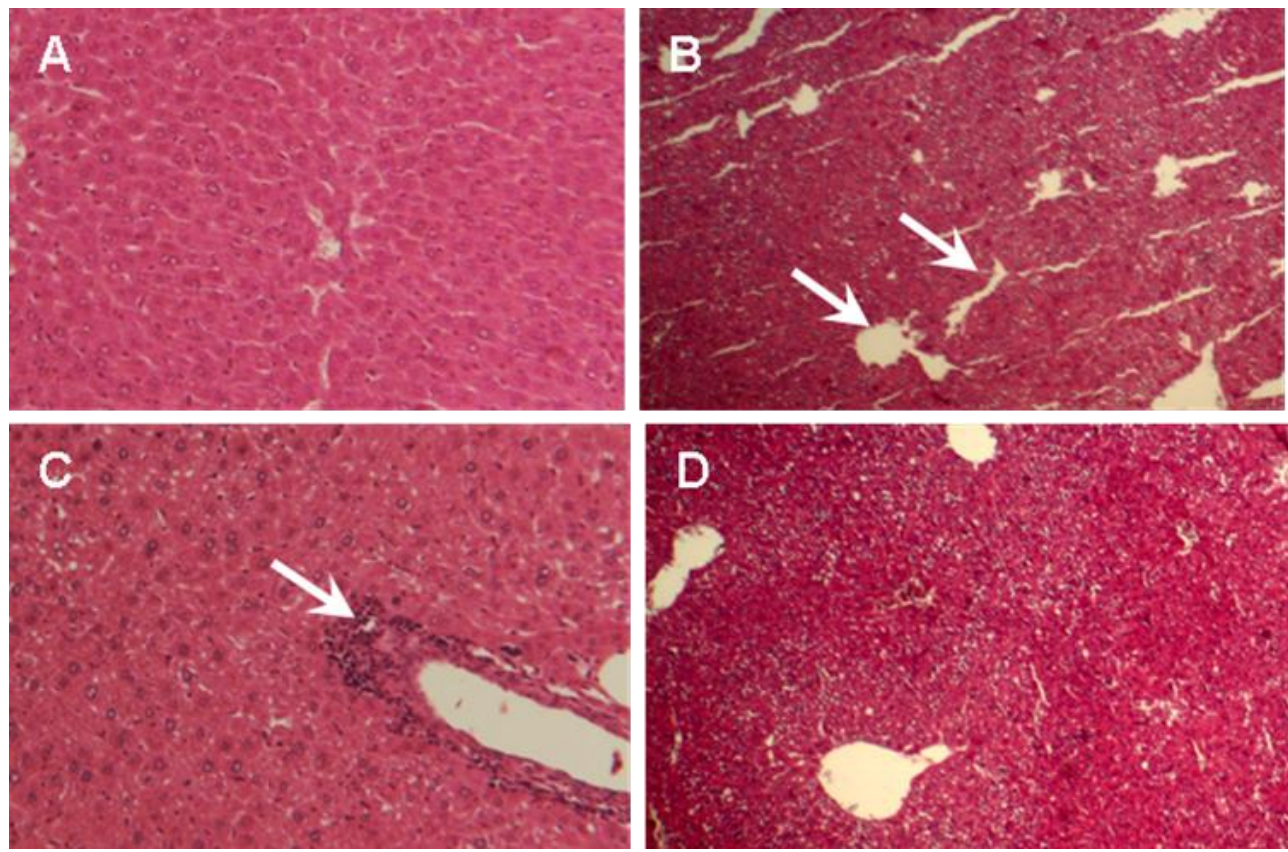

Fig. 1: Micrograph of liver hematoxylin/eosin stained section GX100. (A): Liver section from control mice with normal hepatocytes. (B): Liver from mouse treated with NMU showing disturbance in normal structure of hepatocytes with sinusoidal dilatation (white arrow). (C): Liver from mouse treated with H. aspersa extract, showing immune cells infiltration (white arrow) to the liver. (D): Section of liver from mouse treated by NMU followed by H. aspersa extract showing reparative effect of the extract; diminution of hepatocytes necrosis with normal sinusoid. 

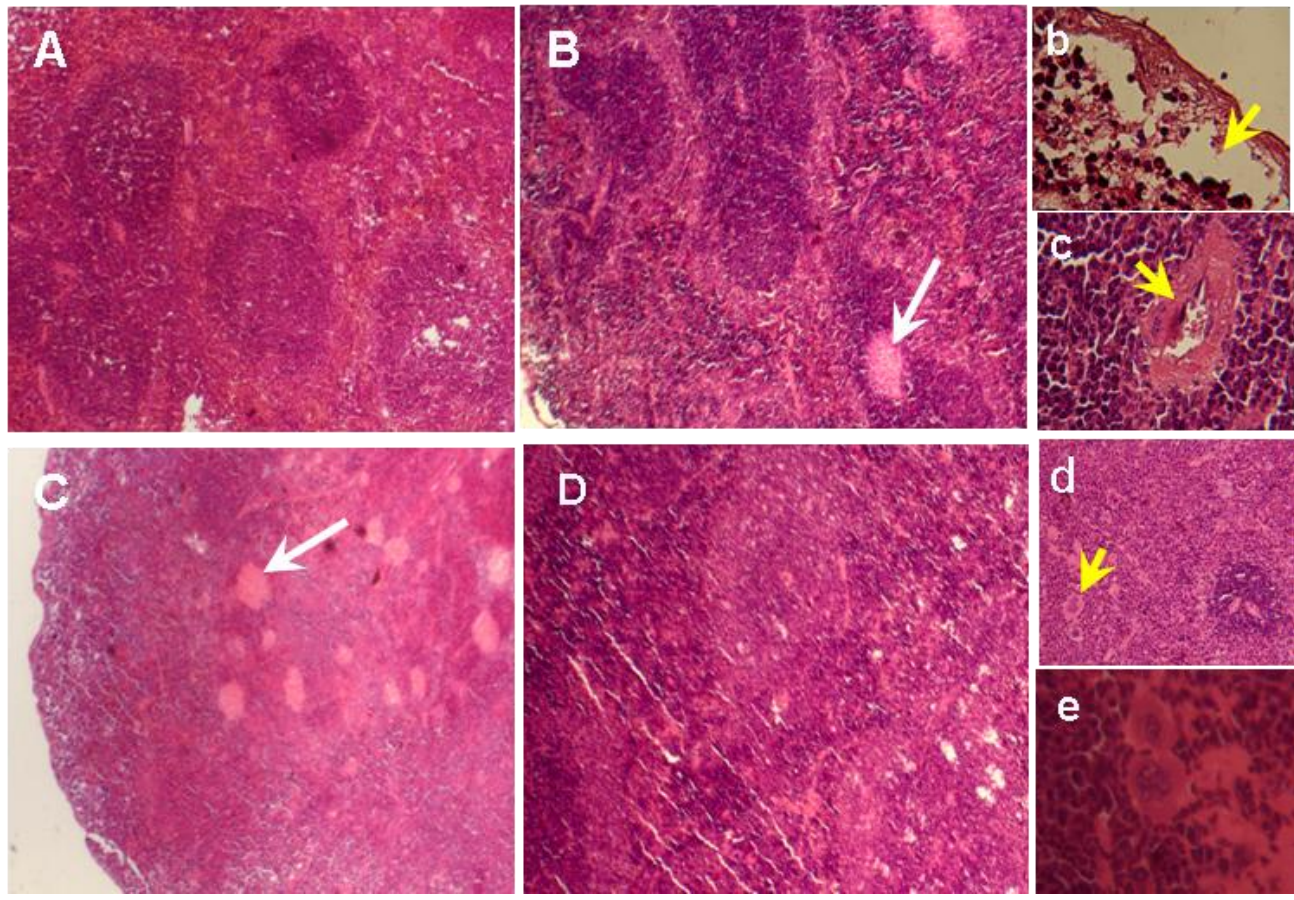

Fig. 2: Micrograph of spleen hematoxylin/eosin stained section. (A): Spleen section from control mice with normal structure, GX100. (B): Spleen from mouse treated with NMU showing disturbance in normal structure, amyloidosis (white arrow) GX100, (b) capsule laceration (yellow arrow) GX400 and (c) hemangioma (yellow arrow) GX400. (C): Spleen of mouse treated with H. aspersa extract, showing periarteial amyloid deposition (white arrow) GX100, (d) foreign giant cell GX400, (e) foreign giant cell GX1000. (D): Section of spleen from mouse treated by NMU followed by H. aspersa extract showing reparative effect of the extract GX100

\section{DISCUSSION}

NMU is one of the widely used chemical carcinogens; it was chosen as a carcinogenic model as it is present in our environment and food. It was suggested to induce oxidative stress and cellular injury.

Our study demonstrates that NMU induces liver alterations; it causes hepatocyte necrosis, sinusoid dilatation and hepatic hemangioma. Liver is an important organ of metabolism, detoxification, storage and excretion of xenobiotics. These agents frequently lead to hepatic necrosis. Different effects of NMU have been reported, it stimulated liver carcinogenesis, hyperplasia of the hepatic cells, congestion of central vein, and dilation of sinusoids. In rabbits, Wang et al., 1993, also reported necrotic areas in the liver associated with vascular changes and proliferation of connective tissue fibers. Moreover, $H$. aspersa extract given after NMU injection restored damage induced by carcinogen and inhibit the carcinogenic process in the liver.

Our result revealed serious damage in the spleen structure; NMU induces capsule alteration, hemorrhage and hemangioma. Similar observations have been recorded by Shashi and Thapar, 2000 in albino rabbits. Amyloidosis was also noted in most of the histological sections of the induced mice. It's a functional disorder marked by abnormal depositions of amyloid proteins in various organs such liver, spleen and kidney (Hosaka et al., 2003). Amyloidosis is classified by a particular precursor protein in two forms: primary amyloidosis (AL amyloidosis). Which result from immunoglobulins light chain deposition and secondary amyloidosis also called AA amyloidosis, where the precursor is the serum amyloid A (Monzawa et al., 2002). Therefore, amyloid deposition in the spleen can be at three major sites; the red pulp, the white pulp, and the blood vessels Ohyama et al., 1990. Histopathological examination of our work showed deposits of amyloid, mainly in red pulp in NMU treated mice and in peri arterial area in $H$. aspersa extract primed mice. In the first case amyloidosis had immunoglobulin light chain as precursor. While in the last case amyloidosis was resulted from serum amyloid A (SAA).

In addition, $H$. aspersa extract induces a transformation of macrophage into giant cells called « foreign body giant cell ». The differentiation process of these cells is unknown. But investigations have reported that it requires IL-4, IL-13 and mannose receptor activation. So it seemed that $H$. aspersa administrated alone stimulates the immune system.

\section{CONCLUSION}

Our results demonstrate that $H$. aspersa extract have a protective effect against liver and spleen injuries induced by a potent carcinogen NMU. It inhibits hemangioma and carcinogenic process in hepatic and spleen vascular system.

\section{REFERENCES}

Guru kumar D, parvathi, meenakshi, rathi M A. Anticancer activity of the ethanolic extract of Crateva nurvala bark against testosterone and MNU-induced prostate cancer in rats. Chinese Journal of Natural Medicines, 2012; 10(5): 0334- 0338 
Hosaka N, Ito M, Taki Y, Iwai H, Toki J, Ikehara S. Amyloid A gastrointestinal amyloidosis associated with idiopathic retroperitoneal fibrosis. Are Pathol Lab Med, 2003; 127: 735-738.

Kim E, Coelho D, Blachier F. Review of the association between meat consumption and risk of colorectal cancer. Nutrition research, 2013; 33(12): 983-994.

Lijinsky W. N- Nitroso compounds in the diet. Mutat Res, 1999; 15: 443(1-2): 129-138.

Liu RH. Potential synergy of phytochemicals in cancer prevention: mechanism of action. J. Nutr, 2004; 134: 3479S-3485S.

Mirvish S. N- nitroso compounds, nitritre and nitrate: possible implications for the causation of human cancer. Proceedings of the Conference on Nitrogen As a Water Pollutant, 2013; 8(4): 195-207.

Mirvish SS. Role of N-nitroso compounds (NOC) and Nnitrosation in etiology of gastric, esophageal, nasopharyngeal and bladder cancer and contribution to cancer of known exposures to NOC. Cancer Lett, 1995; 93(1):17-48.

Monzawa S, Tsukamota T, Omata K, Hosoda K, Araki T, Sugimura K. A case with primary amyloidosis of the liver and spleen: radiologic findings. Eur J Radiol, 2002; 41: 237-241.

Ohyama T, Shimokama T, Yoshikawa Y, Watanabe T. Splenic amyloidosis: correlations between chemical types of amyloid protein and morphological features. Mod Pathol, 1990; 3(4):419-22.
Shashi A, Thapar SP. Histopathology of fluoride-induced hepatotoxicity in rabbits. Fluoride, 2000; 34, 34-42.

Singer S, Kusmierek, JT. Chemical mutagenesis. Annu. Rev. Biochem, 1982; 51, 655-693.

Tricker AR, Preussmann R. Carcinogenic N -nitrosoamines in diet: occurrence, formation, mechanisms and carcinogenic potential. Mutat Res, 1991; 259(3-4):277-89.

Wang J, Zheng, ZA, Zhang LS, Cao DM, Chen KZ, Lu D. An experimental study for early diagnostic features in fluorosis. Fluoride, 1993. 26, 61-65.

\section{How to cite this article:}

Ibtissem EL OUAR, Ihcène DRAA, Hajer ATOUI, Cherifa AGGOUNE, Dalila NAIMI. Protective Effect of Helix Aspersa Extract Against Spleen and Liver Injuries Induced by N-Nitroso Methyl Urea in Mice. J App Pharm Sci, 2015; 5 (11): 113-116. 